University of Missouri, St. Louis

IRL@ UMSL

$11-18-2011$

\title{
Seroprevalence of Malarial Antibodies in Galapagos Penguins (Spheniscus mendiculus)
}

Jamie Lynn Palmer

University of Missouri-St. Louis, jamie.palmer9@gmail.com

Follow this and additional works at: https://irl.umsl.edu/thesis

\section{Recommended Citation}

Palmer, Jamie Lynn, "Seroprevalence of Malarial Antibodies in Galapagos Penguins (Spheniscus mendiculus)" (2011). Theses. 45.

https://irl.umsl.edu/thesis/45

This Thesis is brought to you for free and open access by the UMSL Graduate Works at IRL @ UMSL. It has been accepted for inclusion in Theses by an authorized administrator of IRL @ UMSL. For more information, please contact marvinh@umsl.edu. 


\section{Jamie L. Palmer}

B.S., Biology with an emphasis in Zoology, San Francisco State University - San Francisco, CA. 2005

Seroprevalence of Malarial Antibodies in Galapagos Penguins (Spheniscus mendiculus)

Submitted to the Graduate School at the University of Missouri - Saint Louis in partial fulfillment of the requirements for the degree

Master of Science in Biology with an emphasis in Ecology

December 2011

$\underline{\text { Advisory Committee }}$

Patricia Parker, Ph.D.

Chairperson

Zuleyma Tang - Martinez, Ph.D.

Robert Marquis, Ph.D. 
Palmer, Jamie, 2011, UMSL, p.2

\section{SEROPREVALENCE OF MALARIAL ANTIBODIES IN GALAPAGOS PENGUINS (SPHENISCUS MENDICULUS)}

ABSTRACT: Introduced diseases such as avian malaria can severely impact the health of small populations and have been the cause of species extinctions. Island species are thought to be more highly susceptible to introduced diseases. These populations have likely evolved in the absence of various pathogens making them immunologically naïve to diseases that occur regularly in mainland species. The Galapagos archipelago still preserves $95 \%$ of its species diversity known to have occurred there with most of its species being endemic to the islands. The introduction of Haemosporidian parasites in the genus Plasmodium, which cause avian malaria, have had detrimental impacts on naïve populations in other island systems. Until recently, avian malarial parasites had not been detected in the Galapagos avifauna; however, the presence of Plasmodium parasites has been documented in the endangered Galapagos penguin (Spheniscus mendiculus). Because avian malaria (Plasmodium relictum) causes high mortality in other avian species after initial exposure, there is concern for the conservation of the endemic Galapagos penguin. Using a Plasmodium spp. circumsporozoite protein antigen, we have standardized an enzyme-linked immunosorbent assay (ELISA) to test the level of exposure to the parasite in this species, as indicated by seroprevalence. Low seroprevalence would be consistent with high mortality, whereas high seroprevalence may indicate low Plasmodium-induced mortality under normal conditions. Serum from Galapagos penguins collected between 2004 and 2009 on the Galapagos archipelago was tested for the presence of anti - Plasmodium spp. antibodies. Penguins were also tested for prevalence of avian malaria parasites, determined by polymerase chain reaction 
(PCR). Total seroprevalence of malarial antibodies in this sample group was 97.2\%, while total prevalence of Plasmodium parasites by PCR screening was 9.2\%. This large discrepancy suggests high exposure to the parasite and low Plasmodium - induced mortality, at least under normal environmental conditions. The results of this study also suggest that parasite prevalence may be under-detected through PCR screening and multiple detection methods are necessary to better understand the extent of Plasmodium on the archipelago. It is extremely important to understand the distribution of this parasite on the islands and control any invasive threats before irreversible damage is done.

Key words: seroprevalence, Plasmodium, Spheniscus mendiculus, avian malaria, ELISA, antibody, Galapagos penguin

\section{ACKNOWLEDGEMENTS}

I want to start by thanking my advisor and mentor, Dr. Patricia Parker for all her guidance, support, patience and commitment to this work as well as for all the constructive feedback on every version of this thesis. Thank you to the other members of my committee: Dr. Zuleyma Tang-Martinez and Dr. Robert Marquis for their comments on this manuscript as well as their help and support during this process. Thank you to our collaborator, Dr. Tom McCutchan, who developed the antigen we used and provided many of the reagents used in our testing and for all of his contributions to this work. I am forever grateful to Cindee Rettke, lab manager in our lab and friend, for all of her help, guidance and support in my time at UMSL. I appreciate all of her help and support during the standardizing phase of this work and when troubleshooting problems. Cindee is an essential part of our lab and contributed enormously to this project and taught me 
almost everything I know in the lab. Dan Hartman has been such a big help in my work. I want to thank him for his assistance in the lab with PCR and ELISAs, as well as for making the beautiful map in this paper. Robert Meile was such a wonderful stats teacher and helped with data analysis. Thank you to Jane Merkel at the St. Louis Zoo for providing the previously collected serum samples for testing and for answering so many questions throughout this process. Jane was also part of the teams who collected these samples in the field over the years. Thank you Jane Merkel, F. F. Hernan Vargas, Sharon Deem, Erika Travis, Marylin B Cruz, Gedeminus Valkiūnas, and all the other members of the field teams that collected the samples used in this work. Hernan Vargas and Sharon Deem both provided penguin sampling information for this work. I would also like to thank past and current members of the Parker Lab at UM - St. Louis including Iris Levin, Eloisa Sari, Karen DeMatteo, Jose Luis Rivera, Allisyn Gillet, Paul Zwiers, Jeff Ettling and Jenni Higashiguchi, for always being available to help when needed and to talk through different aspects of this work along the way, for helpful comments and constructive criticism on early manuscripts and presentations and for their constant support throughout this process. Thank you to Audrey Rottinghaus at the University of Missouri - St. Louis, for helping to troubleshoot problems in the early stages of ELISA testing. I am very grateful to Maryann Hempen and Kathy Burney - Miller in the Biology department for all of their administrative help. This work was supported by the Des Lee Collaborative Vision and the St. Louis Audubon Society.

I also want to thank my parents for their support and for being the best day-care for my son William while I continued to work toward my degree. Thank you to my brother Scott and my sister-in-law Kathy for their support and for always being excited about my 
work. Thank you too, to my brother Adam for his support. Finally, thank you to my husband, Nathan, for being so supportive every single day and always acting genuinely interested in my work and to our son William, who is a wonderful baby and who makes everything in life more fun.

\section{INTRODUCTION}

The Galapagos penguin (Spheniscus mendiculus) is endemic to the Galapagos Islands with a population of approximately 1500 individuals (Jimenez - Uzcategui and Vargas, 2008) and is considered endangered (IUCN 2010; Birdlife International, 2011) because its population is perpetually small and experiences significant fluctuations in response to climate (Vargas et al., 2005). The Galapagos archipelago, located on the equator approximately $1000 \mathrm{~km}$ west of continental Ecuador, still preserves $95 \%$ of the species diversity known to have existed there (Gibbs et al., 1999). To date, there have been no extinctions of endemic avian species on the archipelago; however, tourism and human population growth are creating threats to the long - term survival of native species due in part to introduced pathogens, including avian pox (Avipoxvirus) and avian malaria (Plasmodium) (Wikelski et al., 2004; Parker et al., 2006, 2011; Levin et al., 2009).

Island populations are considered immunologically naïve, suggesting that their susceptibility to introduced pathogens should be high (e.g., Hawaiian avifauna: Warner, 1968; van Riper et al., 1986; Atkinson et al., 2000). For example, the relatively recent introduction of mosquitos (Culex quinquefasciatus) and avian malaria (Plasmodium relictum) to the Hawaiian Islands caused severe declines and extinctions of many avian species, particularly in the native honeycreepers (Drepanidinae), from the mid-elevation 
range where C. quinquefasciatus are most concentrated (van Riper et al., 1986; Atkinson et al., 2000). The threat that new pathogens pose to isolated, endemic island species is of great concern. In the Galapagos penguin, this inherent susceptibility to infectious diseases is likely magnified due to the species' small population size and periodic bottlenecks, low genetic diversity (Nims et al., 2008) and very low variation in the major histocompatibility complex (MHC) (Bollmer et al., 2007). Environmental stresses, such as El Nino Southern Oscillation events (ENSO), may increase their disease susceptibility during these periods, threatening the long term survival of the species.

Levin et al. (2009) determined by polymerase chain reaction (PCR) that the vector-borne blood parasite in the genus Plasmodium had a prevalence of $5 \%$ in Galapagos penguins $(\mathrm{n}=362)$. There are two potential Plasmodium vectors on the archipelago. One of which is the non-native mosquito species, Culex quinquefasciatus, a known Plasmodium vector elsewhere which has become established on the Galapagos Islands after first being introduced in the mid - 1980s (Whiteman et al., 2005). Gaining a complete understanding of the extent of the Plasmodium parasite's distribution and its potential long-term effect on the Galapagos penguin is especially important given the knowledge that this parasite (specifically, $P$. relictum and $P$. elongatum) has resulted in high morbidity and mortality in other penguin species, both captive and wild (Stoskopf and Beier, 1979; Fix et al., 1988; Cranfield et al., 1990; Graczyk et al., 1994c; Graczyk et al., 1995a; Graczyk et al., 1995b). For example, malaria-related mortality (due to $P$. relictum and $P$. elongatum) of previously unexposed captive African black-footed penguins (Spheniscus demersus) has been reported to be as high as 50 and 75\% (Stoskopf and Beier, 1979; Cranfield et al., 1990). Plasmodium antibodies have been reported in 
adult African black-footed penguins that are seasonally exposed to an outdoor environment with a competent mosquito vector (Graczyk et al., 1994a). In captive, juvenile African black-footed penguins ( $n=24)$, within five weeks after initial exposure to $P$. relictum and $P$. elongatum parasites, seroprevalence of malarial antibodies was $100 \%$, with a $9 \%$ mortality rate (Graczyk et al., 1994c). Females can pass these antibodies to their chicks, allowing for short-term protection from malarial infection (Graczyk et al., 1994b). Once maternal antibodies levels are no longer detectable, juveniles are then susceptible to infection; in captive African black-footed penguin chicks this occurred at 10 weeks of age (Graczyk et al., 1994b).

After acute Plasmodium relictum infection, birds maintain low-level parasitemia for life and may relapse periodically (Cranfield et al., 1990; Atkinson and van Riper, 1991). In Hawaiian forest birds, acute infections cause high rates of mortality (up to 90\%) (Atkinson et al., 1995) and increase an individual's susceptibility to other stresses (e.g. predators or environmental stress) (Atkinson et al., 2000; Yorinks and Atkinson, 2000). However, individuals that survive acute infections acquire low-intensity chronic infections that are then not detected on blood smears and irregularly detected through PCR screening (Atkinson et al., 2001a; Atkinson et al., 2001b; Jarvi et al., 2002; Woodworth et al., 2005). Survival rates during reinfection are much higher because of acquired immunity to the parasite (Atkinson et al., 2001a; Atkinson et al., 2001b; Jarvi et al., 2002; Woodworth et al., 2005). And in the case of the extremely susceptible Hawaiian amakihi (Hemignathus virens), populations are recolonizing former habitats at low elevations despite the high prevalence of $P$. relictum, indicating a developed immunity and possible host-parasite coevolution (Woodworth et al., 2005). 
We present here the first study measuring seroprevalence of anti - Plasmodium spp. antibodies in the Galapagos penguins by Enzyme - linked Immunosorbent Assay (ELISA). We also use PCR screening techniques to detect the prevalence of Plasmodium parasites in the same birds. While Levin et al. (2009) successfully detected the presence of Plasmodium in the Galapagos penguin through PCR screening, determining anti Plasmodium spp. antibody seroprevalence is necessary given that the parasite has yet to be detected by blood smear examination and it appears that PCR is under-detecting parasite prevalence in the population because the parasite may not be completing its life cycle in this host species (P. G. Parker, unpubl. data). Low parasite detection by PCR and low seroprevalence of malarial antibodies would indicate that the population is highly susceptible to infection and most individuals are not surviving the initial Plasmodium infection. High seroprevalence in the population, however, suggests that many or most penguins are surviving the infections, at least under normal environmental conditions (e.g., not El Nino years) and therefore developing a level of acquired immunity (Atkinson and van Riper, 1991; Cranfield et al. 1994). The use of multiple parasite detection methods will increase our understanding of true Plasmodium prevalence in the population.

We predict high seroprevalence of anti - Plasmodium spp. antibodies in adult penguins, indicating that the population has been broadly exposed. The potential for parasite transmission by an adult penguin at some point in a given year is high since the penguin's range overlaps year - round with the ranges of potential mosquito vectors and because the penguins move regularly throughout their range (Nims et al., 2008) increasing their chance of becoming infected. Adults have most likely been exposed for 
multiple seasons. We predict that Plasmodium infection rates fluctuate seasonally with higher transmission during the wet season, when vector populations are more abundant. Therefore, it is possible juvenile penguins were not exposed prior to sampling and seroprevalence will be low among this group. These young penguins are also no longer protected from infection by maternal antibodies, increasing their susceptibility to infection. Maternally transmitted antibodies only protect chicks for a short period after hatching (Graczyk et al., 1994b). Juveniles, if any, that test positive for anti Plasmodium spp. antibodies are expected to have high antibody levels, indicating current infection because of recent exposure. If the population has, in fact, been exposed to Plasmodium for several seasons, when we compare seroprevalence from our core group of penguins, sampled between 2008 and 2009, to a group of penguins sampled earlier (2004 - 2005), we expect seroprevalence of anti - Plasmodium spp. antibodies to be similarly high in both penguin groups. Alternatively, if it had only recently arrived before the 2004-2005 sampling, seroprevalence may be lower in that sample group than in 2008-2009.

\section{MATERIALS \& METHODS}

\section{Sample collection}

Galapagos penguins were captured in hand nets along the coasts of Isabela and Fernandina islands in the Galapagos Islands (see Travis et al., 2006 for field handling techniques and sample processing). During two field seasons (March - September 2008 and July 2009), serum samples were collected at 8 sites (Figure 1) from a total of 181 Galapagos penguins: 149 adults, 24 juveniles and 8 individuals of undetermined age. 
Sites that were within 10 kilometers of each other were combined for this study and listed as one site. Punta Espinosa and Cañones Sur are both sites that are a combination of two sites (see Figure 1). Serum samples collected from 64 adult penguins during earlier field seasons (March and August 2004 and February 2005) are also used in this study.

\section{Serologic analysis}

Indirect ELISAs were performed using a KPL, Inc. BluePhos® system ELISA kit (Gaithersburg, Maryland) and Nunc brand Immulon II high-binding 96-well ELISA plates (Thermo Scientific, Rochester, New York). Plates were coated with $100 \mu 1$ (2 $\mu \mathrm{g} / \mathrm{ml}$ ) of a circumsporozoite protein (CSP) antigen (GenScript Corp., Piscataway, New Jersey) and incubated at $4^{\circ} \mathrm{C}$ for 24 hours. The CSP is expressed on the surface of Plasmodium sporozoites and asexual parasite stages and this CSP antigen is recognized by antibodies against avian Plasmodium species (T. F. McCutchan, unpubl. data). Plates were then filled with bovine serum albumin (BSA) to block any remaining unbound sites. Next, $100 \mu 1$ of sera from the sampled penguins diluted in BSA (1/100) were added in duplicate and incubated for 17 hours at $4^{\circ} \mathrm{C}$.

A negative control and standard were added to every plate. The standard was also used as a positive control. The negative control, run in triplicate on each plate, was serum from chickens, housed in a mosquito free environment (gift from the Entomology section, Laboratory of Malaria and Vector Research, NIAID, National Institutes of Health, Bethesda, Maryland), diluted in BSA (1/100). The standard, run in duplicate serial dilution in BSA (1/100 to 1/1600) on each plate, was a pool of 3 adult PCR positive Galapagos penguin collected in 2008 (Figure 2). 
Each well was then washed 3 times with $300 \mu 1$ of Imidazole buffered saline with Tween-20 wash solution diluted in water (1/20). Next, $100 \mu 1$ of rabbit anti-Spheniscus demersus IgG (Spring Valley Laboratories, Inc., Woodbine, Maryland) conjugated to alkaline phosphatase, diluted in BSA (1/1000), was added to each well and incubated for two hours at room temperature. The plates went through a second set of three washes with $300 \mu 1$ of the wash solution. Next, $100 \mu 1$ of BluePhos ${ }^{\circledR}$ alkaline phosphatase substrate solution was added to each well. The plates were incubated for 95 minutes at room temperature and read (630nm) on a VERSAmax microplate reader controlled by SOFTmax ${ }^{\circledR}$ Pro software version 4.7 (Molecular Devices Corp., Sunnyvale, California).

The standard was used to determine a positive cut-off absorbance value as well as to make adjustments for plate-to-plate variation. The positive cut-off was calculated as the mean +3 standard deviations (SD) of the standard dilution across 10 plates at which the sample was visually indistinguishable from the negative controls (1/1600 dilution). The mean absorbance value of the standard (1/100 dilution) of the 10 plates acted as the positive control and was used for plate-to-plate variation adjustments. Each individual plate mean standard (1/100 dilution) was compared to this value and absorbance values of all serum samples were adjusted by the difference.

\section{Molecular screening}

Using a standard phenol-chloroform extraction protocol, DNA was extracted from blood (Sambrook et al., 1989). A region of the parasite mitochondrial cytochrome $b$ gene was amplified by PCR using two protocols: 1) primers published in Perkins and Schall (2002) following the protocol in Levin et al. (2009), and 2) primers published in Waldenström et 
al. (2004) following the modified protocol in Levin et al. (2011). Both positive and negative controls were always used. The positive control was a PCR - positive Galapagos penguin that amplified consistently and the negative control consisted of all the PCR reagents minus DNA.

DNA sequencing was performed to identify the PCR - positives as Plasmodium because the screening primers amplify both Plasmodium and Haemoproteus parasites. Using BigDye terminator v3.1 cycle sequencing kits (Applied Biosystems), PCR positive individuals were sequenced in $10 \mu \mathrm{L}$ reactions with a final primer concentration of $1 \mu \mathrm{M}$ and following a standard cycle sequencing program ( 35 cycles of $94^{\circ} 30^{\prime \prime}, 50^{\circ}$ $30^{\prime \prime}, 72^{\circ} 30^{\prime \prime}, 1$ cycle of $\left.72^{\circ} 10^{\prime}\right)$. Ethanol precipitation $(1 \mu \mathrm{L}$ each $3 \mathrm{M} \mathrm{NaOAc}$ and $0.125 \mathrm{M}$ EDTA with $25 \mu \mathrm{L} 100 \%$ ethanol per 20uL PCR product) was used to clean sequencing reactions before sequencing on an $\mathrm{ABI} 3100$ automated sequencer. Sequences were analyzed individually using Seqman (Lasergene). DNA sequences were BLASTed against previously published Plasmodium sequences from Galapagos penguins (GenBank accession numbers: JF833046, JF833047).

\section{Data analysis}

As the data were not normally distributed, nonparametric statistical analyses were performed, using SPSS analytical software (Version 19, IBM, Armonk, NY). MannWhitney $\mathrm{U}$ tests were used to evaluate differences in absorbance distributions by age as well as to compare our sample set with the samples tested from 2004-05. Because of small sample sizes at some sites and non-normality of the absorbance distributions among all eight sites, a Kruskal-Wallis ANOVA was performed to compare absorbance 
distributions across sites. A paired t-test was performed to test for any difference in absorbance values of penguins that were captured in more than one field season. Statistical significance was set at $\mathrm{P}<0.05$.

\section{RESULTS}

The range in absorbance values for the standard at 1/1600 dilution was $0.010-0.037$ with a mean $\pm 3 \mathrm{SD}$ of $0.020 \pm 0.024$, establishing a positive cut-off absorbance value of 0.044. Any individual with an absorbance value at or above 0.044 was considered seropositive. Five out of 181 total penguins fell below the positive cut-off of 0.044 . The negative control absorbance values ranged from -0.009 to 0.009 , with a mean absorbance value of $0.0 \pm 0.003 \mathrm{SD}$.

For the core group of penguins sampled in 2008-2009, a total of 176 individuals of 181 were determined seropositive, yielding anti - Plasmodium antibody seroprevalence of $97.2 \%$. Absorbance values ranged from 0.025 to 2.503 with a median absorbance value and interquartile range (IQR) of 0.108 (.074) (Figure 3). Three individuals had very high absorbance values compared to other individuals tested suggesting possible current infections. The mean absorbance value among these three individuals was 1.801 \pm 0.705 SD with a median absorbance value of 1.807 . All three penguins were adults and were collected at two sites: two at Marielas off the coast of Isabela Island and one at Puerto Villamil, on southern Isabela Island (see Figure 1). The penguin sampled at Puerto Villamil was the only individual, of the three, that tested positive for parasite DNA by PCR. 
Seroprevalence was similarly high across the penguins' range, ranging from 91.2\% to $100 \%$ among sites (Table 1). Kruskal-Wallis tests showed no significant difference among site absorbance value distributions $(\mathrm{H}=12.712, \mathrm{P}=0.079)$ (see Figure 4). The data did, however, violate the following assumptions: 1) equal distribution shape between groups and 2) large sample size variation among sites, increasing the probability of the test not rejecting the null hypothesis (Whitlock and Schluter, 2009).

Adult seroprevalence was $97.3 \%(\mathrm{n}=149)$, and absorbance values ranged from 0.025 to 2.503 . The median absorbance value and IQR for adult penguins was 0.111 (0.067). Juvenile seroprevalence was $95.8 \%(n=24)$ with only one seronegative individual; absorbance values for juveniles ranged from 0.035 to 1.093 with a median absorbance value and IQR of 0.088 (0.105). Seroprevalence for penguins of undetermined age ( $(\mathrm{n}=8)$ was $100 \%$; absorbance values for these individuals ranged from 0.044 to 0.173 , with a median absorbance value and IQR of 0.098 (0.076). A MannWhitney U test determined no significant difference in absorbance distributions between adult and juvenile penguins $(\mathrm{U}=1.54, \mathrm{P}=0.122)$. Frequency distribution comparisons between adults and juveniles are shown in Figure 5. Descriptive statistics of adult and juvenile antibody distributions, as shown by absorbance, are shown in Table 2 .

Sixty-four adult penguins sampled in 2004 or 2005 were tested to determine seroprevalence prior to 2008 - 09. Total anti - Plasmodium spp. antibody seroprevalence for penguins sampled in 2004 and 2005 was $96.8 \%$, with only two individuals falling below the cut - off of an absorbance of 0.044 . Absorbance values ranged from 0.032 to 0.558 with a median absorbance value and IQR of $0.166(0.09)$. A Mann-Whitney U test suggests a significant difference in absorbance distributions between penguins sampled in 
2004 - 05 and those sampled in 2008-09 $(\mathrm{U}=-4.471, \mathrm{P}<0.05)$. The median absorbance value for 2004 - 05 penguins was higher (0.166) than for the 2008 - 09 penguins $(0.108)$. Antibody distributions for $2004-05$ and 2008 - 09 penguins, based on absorbance values, are shown in Figure 6. Descriptive statistics for antibody distributions, as shown by absorbance, comparing these sample groups are shown in Table 2 .

A total of 26/181 penguins sampled in 2008-2009 are recaptures, meaning they were previously sampled at some point between 2003 and 2005. Another five penguins that were first sampled in the 2008 field season were sampled again in 2009. Serum was only available for 10 of the recaptured penguins at both periods of sampling and absorbance value comparisons for these penguins are shown in Table 3. All penguins in Table 3 were recaptured at the same site of original sampling. Antibody levels, as shown by absorbance, of seven penguins decreased over time. Mean decrease in absorbance for these seven individuals was $0.074 \pm 0.068$ SD. The mean increase in absorbance values for the three individuals whose antibody levels increased over time is $0.103 \pm 0.086 \mathrm{SD}$. Results of a paired t-test run on log transformed data determined no significant difference in mean absorbance values between years $(\mathrm{t}=-0.859, \mathrm{P}=0.413)$. One individual (ID 1081), first sampled in 2003, then resampled in 2008 and again in 2009 tested negative for Plasmodium DNA by PCR in each year sampled. Serum was not available from 2003 to test this individual for anti - Plasmodium spp. antibodies; however, serum from this penguin in both the 2008 and the 2009 field seasons was seropositive for anti Plasmodium spp. antibodies (see Table 3), with a 1.9\% decrease in absorbance from 2008 to 2009. Another penguin (ID 5516), first sampled in 2008 and then again in 2009, tested positive for the presence of Plasmodium DNA by PCR as well as seropositive in both 
years. Anti-Plasmodium spp. antibodies, as indicated by absorbance, in this individual increased by $0.4 \%$ ( 0.096 to 0.100 ) from 2008 to 2009 .

\section{Molecular Screening}

Prevalence of Plasmodium DNA, determined by PCR, was 9.4\% (17/181); 6 penguins tested positive only with Waldenström et al. (2004) primers, 3 only with Perkins and Schall (2002) primers, and 8 penguins tested PCR positive using both screening methods (Table 4). All but one PCR - positive penguin were adults. Results of DNA sequencing show all 17 individuals sequenced as the same Plasmodium lineage previously described in Levin et al. (2009) (see GenBank accession numbers: JF833046, JF833047). Absorbance values for serum from these 17 penguins ranged from 0.067 1.807 with a median absorbance value and IQR of $0.129(0.173)$. Interestingly, the individual with the highest absorbance value (2.503) did not test positive for parasite DNA by PCR screening. The remaining PCR - negative penguin $(\mathrm{n}=164)$ absorbance values ranged from $0.025-1.093$, with a median absorbance value and IQR of 0.107 (0.068). Only $2 / 64$ penguins (3.1\%) sampled from 2004 and 2005 were PCR - positive using both Waldenstrom et al. (2004) and Perkins and Schall (2002) primers. The absorbance values for the two PCR - positive individuals were 0.396 and 0.558 . Results of DNA sequencing determined both individuals sequenced as the same Plasmodium lineage previously described in Levin et al. (2009) (see GenBank accession numbers: JF833046, JF833047). 


\section{DISCUSSION}

Here we determined high seroprevalence (97.2\%) of anti - Plasmodium spp. antibodies in the Galapagos penguins sampled in 2008 - 09, despite low detection of Plasmodium parasite DNA by PCR screening (9.4\%). Seroprevalence ranged from 91.2 to $100 \%$ among sample sites, which is expected, given that the Galapagos penguins move regularly throughout their range (Nims et al., 2008). Similarly, high seroprevalence (96.8\%) was determined for the penguins sampled in 2004 and 2005, whereas detection of parasite DNA by PCR was very low (3.1\%). PCR amplifies haemosporidian parasite DNA in the circulating blood, regardless of the parasite's life stage, and therefore may not be detecting gametocytes (Valkiūnas, 2011). This along with the lack of gametocyte detection in blood smears indicates that the parasite may not be completing its life cycle in the penguins. The penguins are likely infected but the absence of gametocytes suggests the possibility of abortive parasite development during the exoerythrocytic stage of development (Olias et al., 2011; Valkiūnas, 2011).

Given that positivity for malarial antibodies requires just a single contact with the parasite and that an acquired immunity develops after the first exposure to the parasite (Atkinson and van Riper, 1991; Cranfield et al., 1994; Graczyk et al., 1994a), our results suggest that parasite intensities in most individuals are too low to be amplified by PCR but the penguins have been broadly exposed to the parasite and are most likely not competent hosts. Jarvi et al. (2002) reported serological methods used to determine antibody seroprevalence (97\%) to be more sensitive in detecting low-intensity chronic Plasmodium relictum infections in Hawaiian passerines (Hemignathus virens) than either microscopy (27\%) or PCR-based methods (61-84\%). 
Seroprevalence between juveniles and adults was predicted to differ, which would have suggested that the juveniles are more susceptible to infection due to lack of previous exposure, but our results suggest no difference in antibody distributions based on absorbance values. Any juveniles not yet infected, following a period of protection by maternally transmitted antibodies, would have fallen below the positive cut-off absorbance value of 0.044 . Our results suggest that juveniles are likely surviving initial infection and may become infected quickly after the maternally transmitted antibodies are no longer providing protection. The presence of maternally transmitted antibodies is ruled out as an explanation for high seroprevalence in juveniles in this study because each juvenile sampled was already fledged. Maternally transmitted anti - Plasmodium spp. antibodies have not yet been tested for in Galapagos penguin chicks. Assuming that the parasite is established in the population, though, recently hatched Galapagos penguin chicks should have high anti - Plasmodium spp. maternal antibody levels. These maternally transmitted antibodies are present in African black - footed chicks in very high levels for approximately 10 weeks after hatching (Graczyk et al., 1994b). In New Zealand, Yellow-eyed penguin chicks (Megadyptes antipodes) remained unaffected after approximately 150 adult penguins died over a two month period, the cause determined to be avian malaria (Graczyk et al., 1995c). Chick survival was likely due to high maternally transmitted antibody titers that protected them from the outbreak (Graczyk et al., 1995c).

The majority of documented cases of high mortality and morbidity due to malaria outbreaks in penguins occur in captive environments, where immunologically naïve penguins are introduced to outdoor environments with Culex sp. mosquitos that transmit 
$P$. relictum and $P$. elongatum. Typically, these penguins are wild - caught individuals relocated from climates that lack Plasmodium sp. parasites or were only seasonally exposed to the parasite during migration (Stoskopf and Beier, 1979; Fix et al., 1988; Cranfield et al., 1990; Graczyk et al., 1995a). The penguins that do not survive Plasmodium infections die quickly after initial exposure, before they develop the appropriate humoral response to infection (Graczyk et al., 1994a). Clinical disease and cause of mortality due to Plasmodium infection is, in these cases, easier to observe and diagnose after initial infection (Graczyk et al., 1994c), yet even in captive populations, signs of parasitemia and clinical disease are often absent (Fix et al., 1988). Only 1/38 wild-caught Magellanic penguins (S. magellanicus) that died of malaria ( $P$. relictum) at an Iowa zoo had detectable parasitized erythrocytes by blood smear examination (13\% infected cells; $11 \%$ meronts, $2 \%$ gamonts) (Fix et al., 1988).

All of the Galapagos penguins sampled in our study were in apparently good health and did not show signs of clinical disease. If they are dying from infection, the carcasses are unlikely to be found because they are either quickly eaten by predators or scavengers, or are washed away, increasing the challenge of determining if any are becoming sick due to disease (Bennett et al., 1993). Our results suggest that individuals are able to survive infection given that many penguins were recaptured on two and, in a single case, three different occasions across several years in seemingly good health. High seroprevalence in samples collected between 2004 and 2005 (96.8\%) indicates that penguins were first exposed to the parasite earlier than 2004, and these penguins were also reported to have been in seemingly good health (Travis et al., 2006). The median antibody levels between the two sets of years were determined to be significantly higher 
in $2004-05$ than $2008-09$ (Mann-Whitney $\mathrm{U}, \mathrm{U}=-4.471, \mathrm{P}<0.05$ ). Fluctuations in the distribution of antibody levels within the population over time is expected, given the number of environmental stressors, such as fluctuations in weather conditions or changes in prey abundance, that might affect individual stress levels and susceptibility.

High seroprevalence suggest low Plasmodium - related mortality in the population under normal environmental conditions, but what effect is Plasmodium having during stressful conditions? The Galapagos penguins are heavily impacted by El Niño Southern Oscillation (ENSO) events that cause surface water temperatures to increase and food supplies to decrease (Vargas et al. 2006). Following the last two strong ENSO events, the penguin population crashed by 77\% (1982-83) and 65\% (1997-98) (Vargas et al., 2006). Given that the ENSO events drastically decrease food supply for the penguins, and because stress is shown to increase susceptibility to Plasmodium infection (Graczyk et al., 1995a), the stress of an ENSO event that may trigger a recurrence of Plasmodium infection could be devastating for this already endangered species. Previous collapses during ENSO events have been attributed to starvation (Vargas et al., 2006), but perhaps some of the mortality may have been due to a combination of a recurrence of Plasmodium infection and the increase of environmental stress on the penguins. If the 1982-83 ENSO event coincided with the establishment of the mosquito vector Culex quinquefasciatus on the islands (first documented in the 1980's: Peck et al., 1998), high environmental stress may have increased the level of malarial infections in the penguins, and the combined effects of ENSO and Plasmodium introduction could have caused the extreme population decline during that event. Those that survived the initial infection would have been the older, healthier individuals that had then developed some immunity. 
And as ENSO events increase in frequency, the frequency of Plasmodium - related relapse and mortality could also increase.

Stress has been documented to affect seroprevalence in wild-caught African black-footed penguins in South Africa. Higher anti - Plasmodium spp. antibody seroprevalence (38 and 62\%) was reported in wild penguins held in captivity for rehabilitation after an oil spill, than in non-oiled birds (29 - 35\%) (Graczyk et al., 1995a). A comparison of antibody levels in the population of Galapagos penguins over a long period of time will provide a better understanding of disease related fluctuations in the Galapagos penguins during stressful periods. Knowing the distribution of antibody levels in seropositive penguins during ENSO years could potentially determine if relapse infections increase during those periods.

There are a number of factors that would be expected to increase the Galapagos penguin's susceptibility to introduced diseases like Plasmodium including geographic isolation and a small total population size that is known to go through severe bottlenecks. Compared to other penguin species, the Galapagos penguin has lower genetic diversity when looking strictly at the average number of alleles per locus (3.0 alleles per locus) (see Nims et al., 2008). The level of gene flow, however, between smaller breeding colonies is high indicating that individuals move regularly throughout their range which increases the chance of introduced diseases to spread throughout their distribution (Nims et al., 2008). Until recently, the Galapagos penguins have been relatively disease - free, with all individuals reported by Travis et al. (2006) to be seronegative for all viruses tested, including West Nile Virus, indicating lack of exposure. 
The Galapagos penguins also have very low MHC variability (three polymorphic sites and a nucleotide diversity of 0.01 in 157 base pair sequence of the exon 2 gene) as compared to other penguin species (see Bollmer et al., 2007). High variability of the MHC genes is important for the recognition of foreign antigens by an individual's immune system, especially to foreign pathogens, and a decrease in MHC variability might increase a species susceptibility to introduced diseases. It has been noted that some species with reduced numbers of MHC alleles may still be able to recognize a wide range of pathogens because the remaining alleles are often highly divergent (Hendrick et al., 2000). In the Galapagos penguins, the average amino acid divergence among alleles was only $4 \%$, much lower than other species that also show very low MHC diversity (see Bollmer et al., 2007). With such low MHC variability in the Galapagos penguins, susceptibility to initial infection would likely be very high. However, what we see is high seroprevalence of anti-Plasmodium spp. antibodies suggesting they are surviving with the infections. Bollmer et al. (2007) propose that demographic factors like periodic bottlenecks may likely be a reason for the lack of MHC diversity. Given our results, it is possible that the cause of such low MHC variability in the Galapagos penguins might be due to a selective sweep through the population due to the introduction of the Plasmodium parasites. If so, the only individuals that survived initial infections are those that have the alleles for pathogen resistance, which would explain survival in the face of so many factors that would likely select against it. And if the introduction of Plasmodium coincided with a particularly strong ENSO event in the past, the combination of effects could have increased mortality in the population during that event. 
For now, the penguins are able to cope and survive with this one introduced pathogen, but might not be so lucky in the presence of multiple pathogens.

High seroprevalence of malarial antibodies (23-91\%) similar to what we report in this study has been determined in wild, Yellow-eyed penguins in New Zealand with higher seroprevalence at more northern sites where penguin populations overlap with higher concentrations of Culex spp. mosquitos (Graczyk et al. 1995c). The Galapagos archipelago sits on the Equator at latitude $0^{\circ} 54^{\prime} \mathrm{S}$, which is more northern than the yellow-eyed penguin range; therefore, it is not surprising that seroprevalence is higher in the Galapagos penguins at $97.2 \%$. As the only tropical-breeding penguin, the Galapagos penguin is the only one found at latitudes where mosquitoes might be expected year round. Sturrock and Tompkins (2007) failed to detect Plasmodium sp. DNA in wild, Yellow-eyed penguins $(n=143)$ from New Zealand and attribute the discrepancy of absolute lack of parasite DNA detection but serological results indicating high exposure to the parasite (Graczyk et al., 1995c), as being either an overestimation of exposure by serological tests, or that the initial infections occur in the penguins at an age that is poorly sampled for their study. High antibody levels to Plasmodium spp. have also been found in other endemic island avian species (Atkinson et al., 2001b; Jarvi et al., 2002; Woodworth et al., 2005) including wild populations of other penguin species (Graczyk et al., 1995a; Graczyk et al., 1995c).

Variations in anti - Plasmodium spp. antibody seroprevalence have been reported for wild and captive populations of six penguin species: African black-footed penguins $($ wild population $=52 \%$ seroprevalence $)$, Adelie penguins $($ Pygoscelis adeliae $)(0 \%)$, Gentoo penguins (P. papua) (33\%), King penguins (Aptenodytes patagonicus) (58\%), 
little blue penguins (Eudyptula minor) (92\%), captive Magellanic penguins ( $S$. magellanicus) (43\%), and captive yellow-eyed penguins (Megadyptes antipodes) (100\%) (Graczyk et al., 1995b). Seroprevalence of Plasmodium spp. antibodies was higher in species that have overlapping distributions with a mosquito vector (Culex spp.) ranging from $33 \%$ in Gentoo penguins from French subantarctic territories to $100 \%$ in Yelloweyed penguins from New Zealand (Graczyk et al., 1995b). Species with higher seroprevalence of anti - Plasmodium spp. antibodies are the more northern ranging penguins with potential parasite exposure throughout the year, whereas species with lower seroprevalence may only be exposed to competent Plasmodium sp. vectors during migration, allowing some penguins to remain unexposed (Graczyk et al., 1995b). Our results show seroprevalence in the Galapagos penguins, the most northern ranging penguin species, to be consistent with this trend at $97.2 \%$.

The suspected Plasmodium vector on the Galapagos archipelago is the mosquito species Culex quinquefasciatus which was first documented on the Galapagos Islands in the 1980s (Peck et al., 1998) and has since been well established (Whiteman et al., 2005). Culex quinquefasciatus is a known Plasmodium vector elsewhere (Atkinson et al., 2000). The range of this fresh water breeding mosquito on the archipelago is limited since there are very few fresh water sources outside of human inhabited areas. The only recorded native species of mosquito on the islands that are known to bite birds, Aedes taeniorhynchus, may also be a potential vector of Plasmodium. Given that $A$. taeniorhynchus breeds in brackish water, is known to take blood meals from birds, and that some of the penguins testing positive for Plasmodium infection were sampled in areas lacking regular fresh water sources, this native species cannot be discounted as a 
possible vector. Therefore, it is important to determine not only the vector, but also which bird species on the island is acting as a reservoir for the parasite. If the penguins are not competent hosts for the parasite, there must be another species, or multiple species, on the archipelago acting as the reservoir for the transmission of Plasmodium.

Recapture data of seropositive penguins and very high anti - Plasmodium spp. seroprevalence in both $2008-09(97.2 \%)$ and $2004-05(96.8 \%)$ indicates that the Galapagos penguins are surviving in the presence of Plasmodium parasites, at least under normal environmental conditions. Our results also give strong support to the idea that more than one detection method should be used to determine the extent of Plasmodium in populations that may not be competent hosts for the parasite. Similarly, even in populations that are capable of transmitting the malaria parasite, multiple detection methods are necessary given that both blood smear and PCR techniques can underestimate the extent of Plasmodium infections (Jarvi et al., 2002). And finally, understanding the transmission dynamic (e.g. reservoir species and vector species) of this parasite on the archipelago is essential for the long - term conservation of the Galapagos penguin and other susceptible endemic avian species. If it is shown that either the mosquito vector or reservoir species for Plasmodium transmission is a non - native species, steps can be implemented for their eradication. 


\section{LITERATURE CITED}

Atkinson, C. T. and C. van Riper III. 1991. Pathogenicity and epizootiology of avian haematozoa: Plasmodium, Leucocytozoon, and Haemoproteus. In Bird-parasite interactions, ecology, evolution and behavior. J. E. Loye and M. Zuk (eds.). Oxford University Press, Oxford, U.K., p19-48.

Atkinson, C.T., K. L. Woods, R. J. Dusek, L. S. Sileo, and W. M. Iko. 1995. Wildlife disease and conservation in Hawaii: Pathogenicity of avian malaria (Plasmodium relictum) in experimentally infected Iiwi (Vestiaria coccinea). Parasitology 111, S59-S69.

Atkinson, C.T., R. J. Dusek, K. L. Woods, and W. M. Iko. 2000. Pathogenicity of avian malaria in experimentally infected Hawaii Amakihi. Journal of Wildlife Diseases 36(2), 197-204.

Atkinson, C. T., R. J. Dusek, and J. K. Lease. 2001a. Serological responses and immunity to superinfection with avian malaria in experimentally infected Hawaii Amakihi. Journal of Wildlife Diseases, 37(1), 20-27.

Atkinson, C. T., J. K. Lease, B. M. Drake, and N. P. Shema. 2001b. Pathogenicity, serological responses, and diagnosis of experimental and natural malarial infections in native Hawaiian Thrushes. Condor 103(2), 209-218.

Bennett, G.F., M. A. Peirce, and R. W. Ashford. 1993. Avian haematozoa: mortality and Pathogenicity. Journal of Natural History 27, 993-1001.

BirdLife International. 2011. Species factsheet: Spheniscus mendiculus. Downloaded from http://www.birdlife.org on 24/05/2011

Bollmer, J. L., F. H. Vargas and P.G. Parker. 2007. Low MHC variation in the endangered Galápagos penguin (Spheniscus mendiculus). Immunogenetics 59, 593-602.

Cranfield, M. R., M. L. Shaw, F. B. Beall, M. L. Skjoldager, and D. M. Ialeggio. 1990. A review and update of avian malaria in the African penguin (Spheniscus demersus). Proceedings of the American Association of Zoo Veterinarians. pp. 234-248.

Cranfield, M.R., T. K. Graczyk, F. B. Beall, D. M. Ialeggio, M. L. Shaw and M. L. Skjoldager.

1994. Subclinical avian malaria infections in African Black-footed penguins (Spheniscus demersus) and induction of parasite recrudescence. Journal of Wildlife Diseases 30, 372-376. 
Fix, A. S., C. Waterhouse, E. C. Greiner, and M. K. Stoskopf. 1988. Plasmodium relictum as a cause of avian malaria in wild-caught Magellanic penguins (Spheniscus magellanicus). Journal of Wildlife Diseases, 24(4), 610-619.

Gibbs, J.P., H. L. Snell, and C. E. Causton. 1999. Effective monitoring for adaptive wildlife management: lessons from the Galapagos Islands. Journal of Wildlife Management 63, 1055-1065.

Graczyk, T.K., M. R. Cranfield, M. L. Skjoldager, and M. L. Shaw. 1994a. An ELISA for detecting anti - Plasmodium spp. antibodies in African black-footed penguins (Spheniscus demersus). Journal of Parasitology 80(1), 60-66.

Graczyk, T. K., M. R. Cranfield, M. L. Shaw, and L. E. Craig. 1994b. Maternal antibodies against Plasmodium spp. in African black-footed penguin (Spheniscus demersus) chicks. Journal of Wildlife Diseases 30(3), 365-371.

Graczyk, T. K., M. R. Cranfield, T. F. McCutchan, and E. J. Bicknese. 1994c. Characteristics of naturally acquired avian malaria infections in naïve juvenile African black-footed penguins (Spheniscus demersus). Parasitology Research 80, 634-637.

Graczyk, T.K., J. J. Brossy, A. Plös, and M. K. Stoskopf. 1995a. Avian malaria seroprevalence in Jackass penguins (Spheniscus demersus) in South Africa. Journal of Parasitology 81(5), 703-707.

Graczyk, T. K., M. R. Cranfield, J.J. Brossy, J.F. Cockrem, P. Jouventin, P.J. Seddon. 1995b. Detection of Avian Malaria Infections in Wild and Captive Penguins. Journal of Helminthology Soc. Wash. 62(2), 135-141.

Graczyk, T.K., J.F. Cockrem, M.R. Cranfield, J.T. Darby, and P. Moore. 1995c. Avian malaria seroprevalence in wild New Zealand penguins. Parasite, 2, 401-405.

Grim, K.C., E. Van der Merwe, M. Sullivan, N. Parsons, T. McCutchan, and M. Cranfield. 2003. Plasmodium juxtanucleare associated with mortality in Blackfooted penguins (Spheniscus demersus) admitted to a rehabilitation center. Journal of Zoo and Wildlife Medicine 34(3), 250-255.

Hendrick, P. W., K. M. Parker, G. A. Gutiérrez-Espeleta, A. Rattink, K. Lievers. 2000. Major histocompatibility complex variation in the Arabian Oryx. Evolution 54, 2145-2151.

IUCN. 2010. Spheniscus mendiculus. IUCN Red List of Threatened Species Version 2010.4. <http://www.iucnredlist.org>. Downloaded on 24 May 2011.

Jarvi S.I., J. J. Schultz, and C. T. Atkinson. 2002. PCR diagnostics underestimate the prevalence of avian malaria (Plasmodium relictum) in experimentally-infected passerines. Journal of Parasitology 88, 153-158. 
Jiménez-Uzcátegui, G. and F. H. Vargas. 2008. Censo del pingüino de Galápagos y cormorán no volador 2008. Report to the Charles Darwin Foundation and the Galapagos National Park Service, Charles Darwin Foundation, Puerto Ayora, Santa Cruz, Galapagos, pp. 1-19.

Levin, I.I., D. C. Outlaw, F. H. Vargas, and P. G. Parker. 2009. Plasmodium blood parasite found in endangered Galapagos penguins (Spheniscus mendiculus). Biological Conservation 142, 3191-3195.

Levin, I. I., G. Valkiūnas, D. Santiago-Alarcon, L. L. Cruz, T. A. Iezhova, S. L. Obrien, F. Hailer, D. Dearborn, E. A. Schreiber, R. C. Fleischer, et al. 2011. Hippoboscidtransmitted Haemoproteus parasites (Haemosporida) infect Galapagos pelecaniform birds: Evidence from molecular and morphological studies, with a description of Haemoproteus iwa. International Journal of Parasitology 41, 10191027.

Olias, P., M. Wegelin, W. Zenker, S. Freter, A. D. Gruber, and R. Klopfleisch. 2011. Avian Malaria Deaths in Parrots, Europe. Emerging Infectious Diseases 17(5), 950-952.

Nims, B.D., F. H. Vargas, J. Merkel, and P. G. Parker. 2008. Low genetic diversity and lack of population structure in the endangered Galapagos penguin (Spheniscus mendiculus). Conservation Genetics 9, 1413-1420.

Parker, P. G., N. K. Whiteman, and R. E. Miller. 2006. Perspectives in Ornithology: ConservationMedicine in the Galápagos Islands: Partnerships among Behavioral, Population and Veterinary Scientists. Auk 123, 625-638.

Parker, P.G., E. L. Buckles, H. L. Farrington, K. Petren. N. K. Whiteman, R. E. Ricklefs, J. L. Bollmer, and G. Jimenez-Uzcategui. 2011. 100 years of Avipoxvirus on the Galapagos Islands. PLoS ONE 6(1): e15989. doi:10.1371/journal.pone.0015989

Peck, S.B., J. Heraty, B. Landry, and B. J. Sinclair. 1998. Introduced insect fauna of an oceanic archipelago: The Galápagos Islands, Ecuador. American Entomologist 44, 218-237.

Perkins, S. L. and J. J. Schall. 2002. A molecular phylogeny of malarial parasites recovered from cytochrome $b$ gene sequences. Journal of Parasitology 88(5), 972978.

Sambrook J., E. F. Fritsch, and T. Maniatis. 1989. Molecular cloning : a laboratory manual (Cold Spring Harbor Laboratory, Cold Spring Harbor, N.Y.) 2nd Ed.

Stoskopf, M. K., and J. R. Beier. 1979. Avian malaria in African black-footed penguins. Journal of the American Veterinary Medical Association 175, 944-947. 
Travis, E. K., F. H. Vargas, J. Merkel, N. Gottdenker, R. E. Miller, and P. G. Parker. 2006. Hematology, serum chemistry, and serology of the Galápagos Penguin in the Galápagos Islands, Ecuador. Journal of Wildlife Diseases 42, 625 - 632.

Valkiūnas, G. 2011. Haemosporidian vector research: marriage of molecular and microscopical approches is essential. Molecular Ecology 20, 3084 - 3086

Van III, C., S. G. Van Riper, M. L. Goff, and M. Laird. 1986. The epizootiology and ecological significance of malaria in Hawaiian Island birds. Ecological Monographs 56, 327 - 344.

Vargas, F. H., C. Lougheed, and H. Snell. 2005. Population size and trends of the Galapagos penguin Spheniscus mendiculus. Ibis 147, 367 - 374.

Vargas, F.H., S. Harrison, S. Rea, and D. W. Macdonald. 2006. Biological effects of El Niño on the Galapagos penguin. Biological Conservation 127, $107-114$.

Waldenström, J., S. Bensch, D. Hasselquist, and Ö. Östman. 2004. A new nested polymerase chain reaction method very efficient in detecting Plasmodium and Haemoproteus infections from avian blood. Journal of Parasitology 90(1), 191 194.

Warner, R.E., 1968. The role of introduced diseases in the extinction of the endemic Hawaiian avi-fauna. Condor 70, $101-120$.

Whiteman, N. K., S. J. Goodman, B. J. Sinclair, T. Walsh, A. A. Cunningham, L. D. Kramer, and P. G. Parker. 2005. Establishment of the avian disease vector Culex quinquefasciatus Say, 1823 (Diptera: Culicidae) on the Galapagos Islands, Ecuador, Ibis 147, 843 - 847.

Whitlock, M. C. and D. Schluter. 2009. The Analysis of Biological Data. Roberts and Company publishing. $342-344$.

Wikelski, M., J. Foufopoulos, H. Vargas, and H. Snell. 2004. Galapagos Birds and Diseases: Invasive Pathogens as Threats for Island Species. Ecology and Society 9(1): 5 .

Woodworth, B. L., C. T. Atkinson, D. A. LaPointe, P. J. Hart, C. S. Spiegen, E. J. Tweed, C. Henneman, J. LeBrun, T. Denette, R. DeMots, et al. 2005. Host population persistence in the face of introduced vector-borne diseases: Hawaii amakihi and avian malaria. PNAS 102(5), 1531-1536.

Yorinks N. and C.T. Atkinson. 2000. Effects of malaria (Plasmodium relictum) on activity budgets of experimentally infected juvenile Apapane (Himatione sanguinea). Auk 17, 731-738. 


\section{FIGURES}

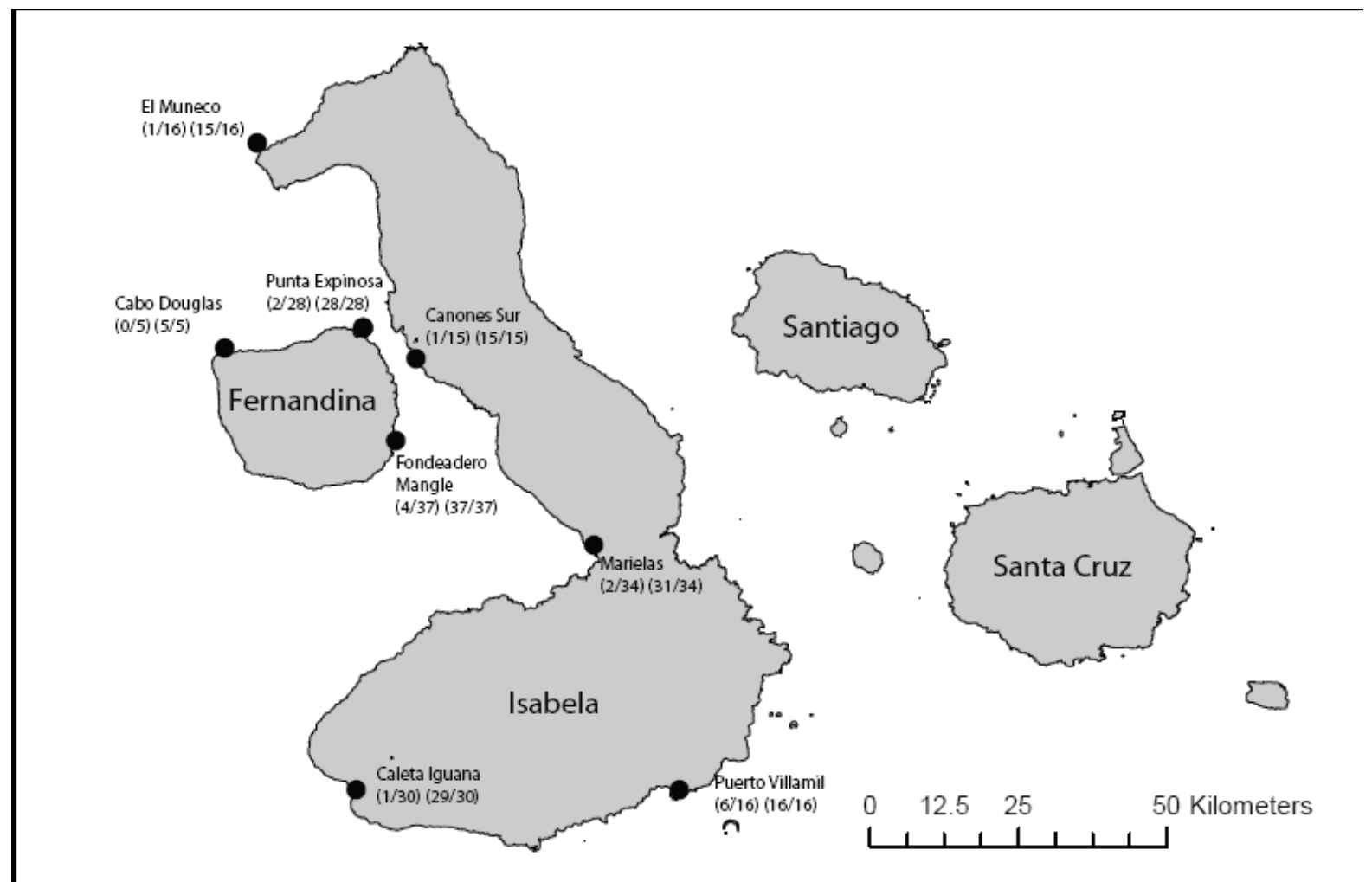

Figure 1. Map of 2008-2009 sample sites. Total of eight sites located on Isabela and Fernandina islands. Numbers in parentheses show prevalence of parasite DNA by PCR and Seroprevalence (no. PCR positive/total) (no. seropositive/total). 


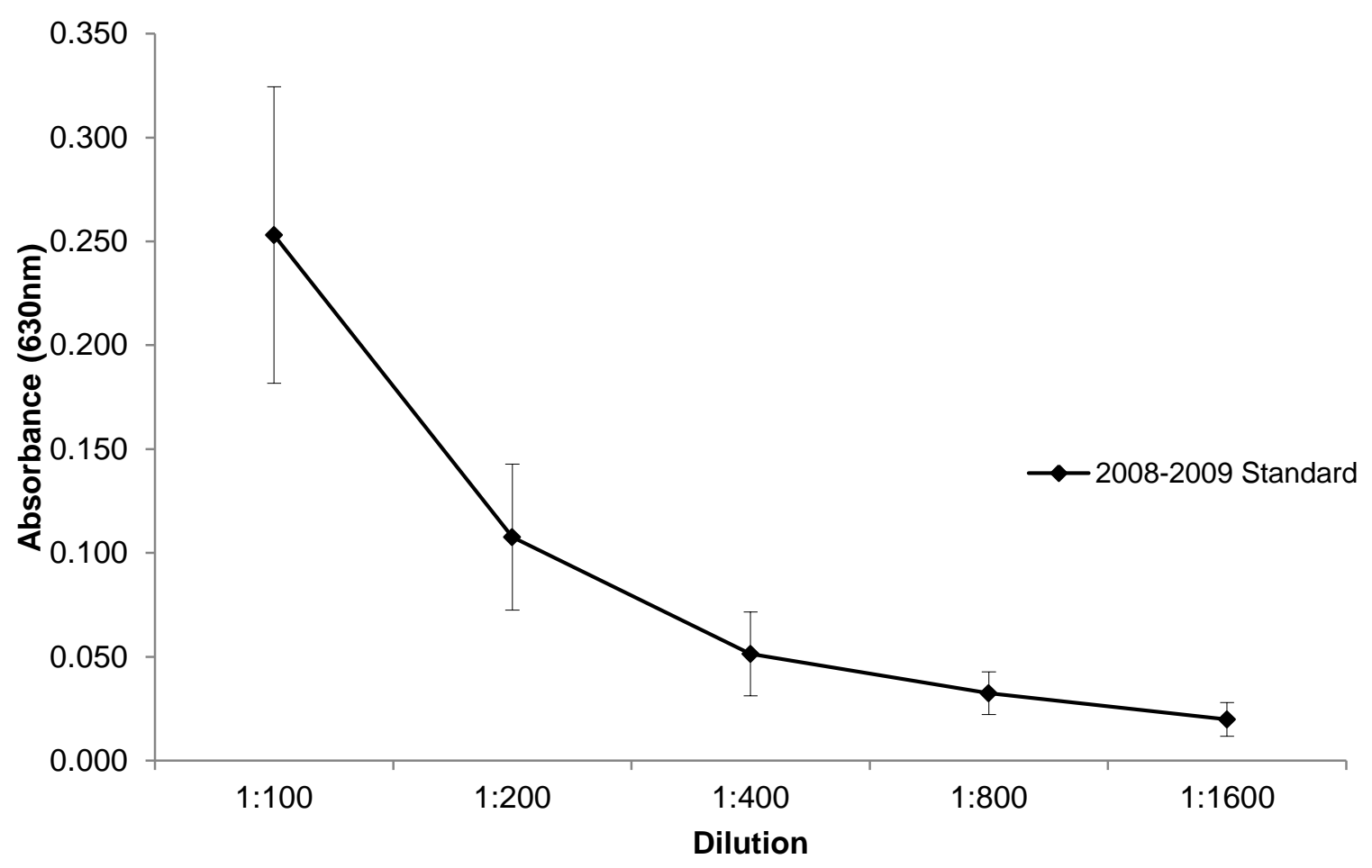

Figure 2. Standard: pool of 3 penguins from the 2008 field season that amplify as Plasmodium on PCR, run in serial dilution from $1 / 100$ to $1 / 1600$ on each plate. Curve includes the mean absorbance values across 10 plates \pm SD.

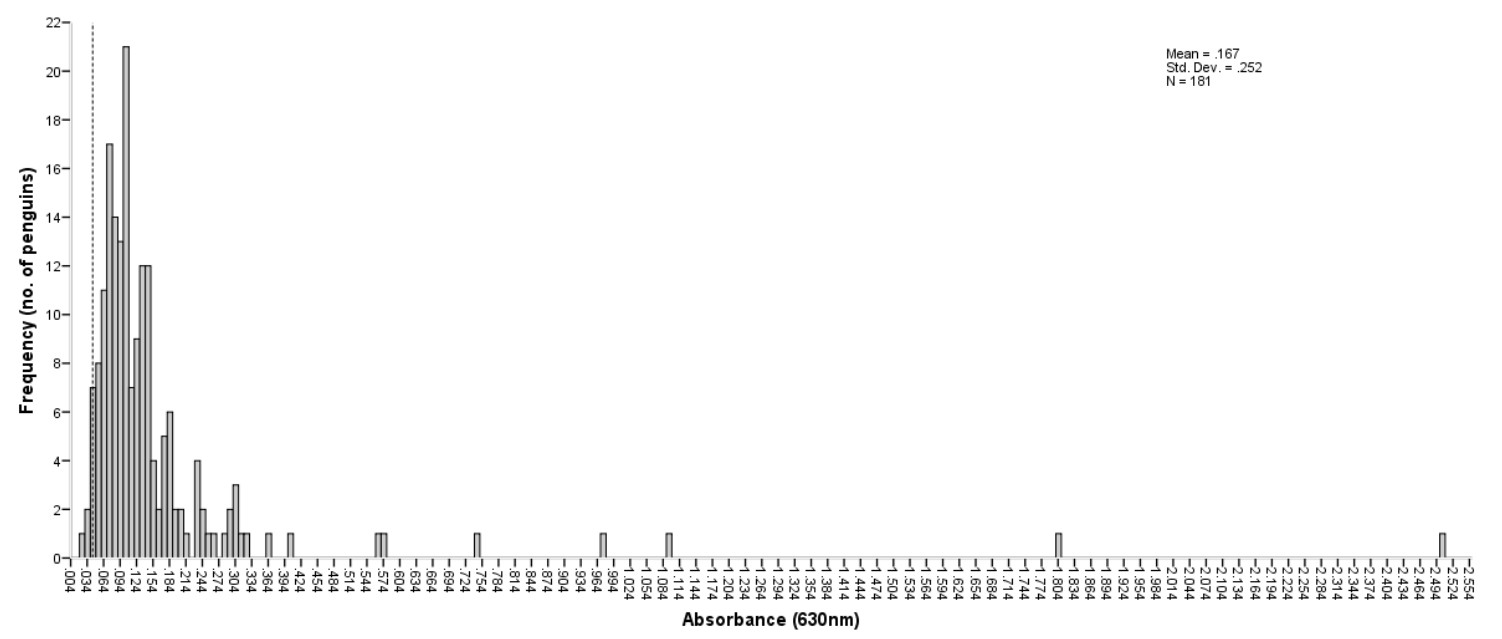

Figure 3. Frequency distribution of antibody levels, as shown by absorbance $(630 \mathrm{~nm})$ of 181 total penguins, 149 adults, 24 juveniles and 8 penguins of undetermined age.

Positive cut-off indicated by dotted line at an absorbance of 0.044 . 


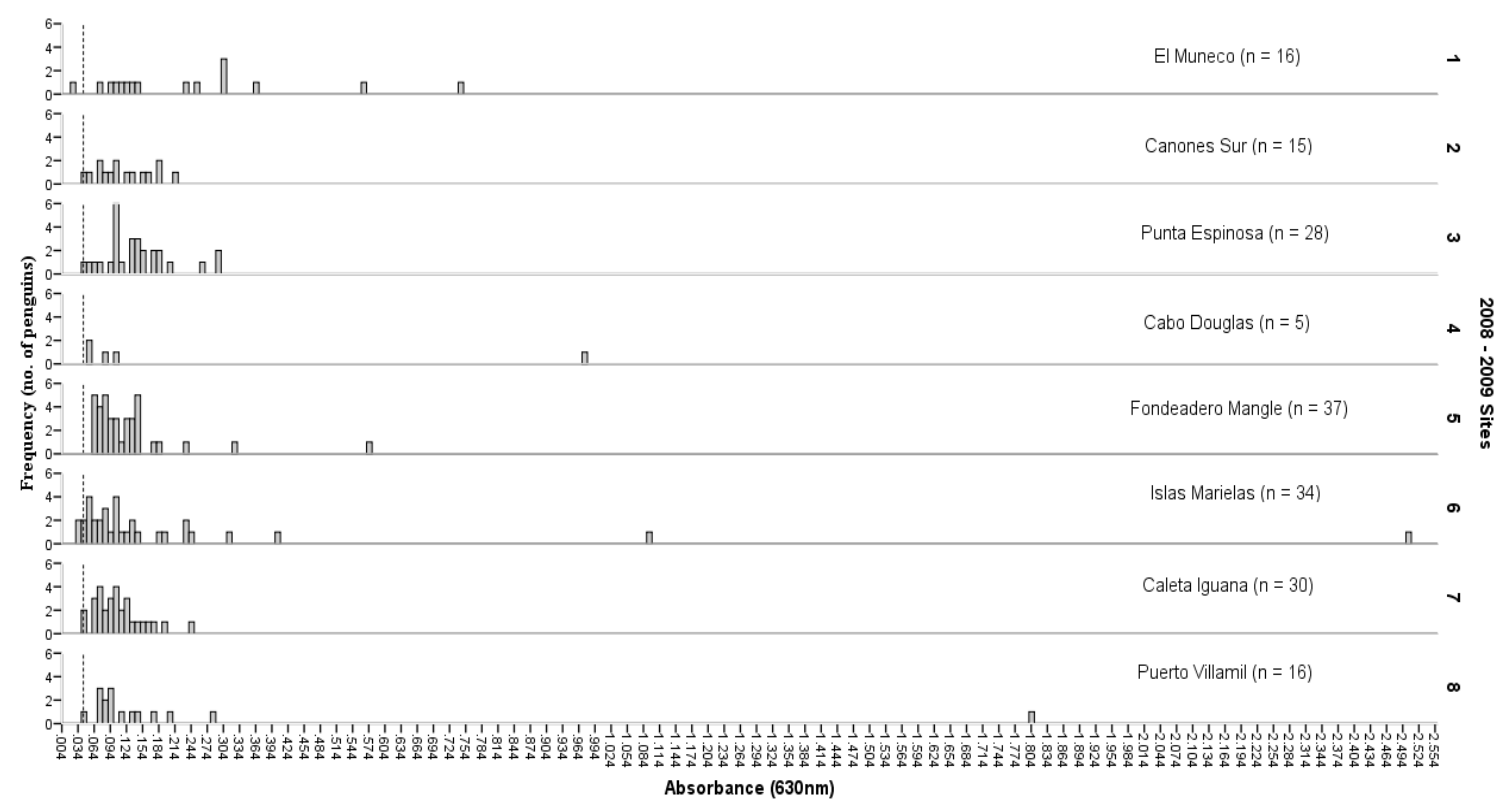

Figure 4. Frequency distributions of antibody levels, as shown by absorbance $(630 \mathrm{~nm})$, for all eight sites sampled in 2008-2009. Sites are listed in order from north to south. Positive cut-off indicated by dotted line at an absorbance of 0.044 .

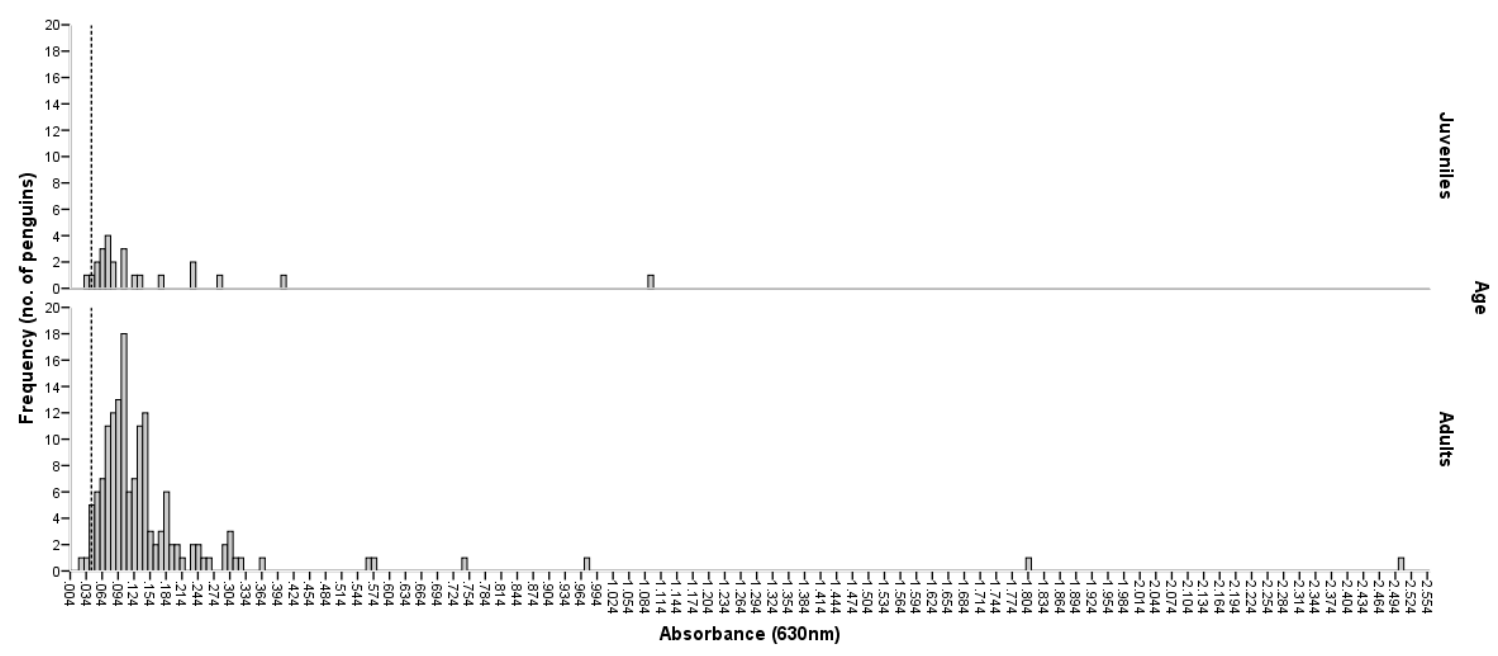

Figure 5. Frequency distributions of antibody levels, as shown by absorbance $(630 \mathrm{~nm})$, of 2008 - 2009 penguin samples by age. Juveniles $(n=24)$, Adults $(n=149)$. Positive cut-off indicated by dotted line at an absorbance of 0.044 . 


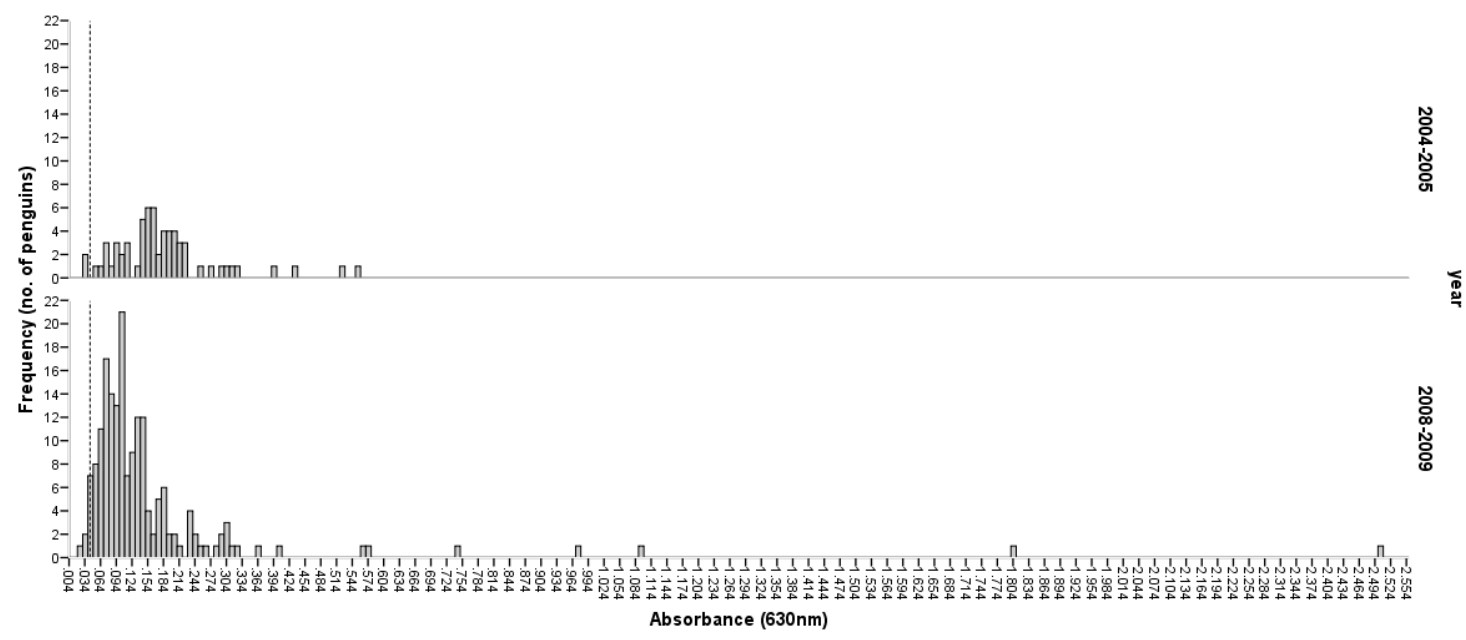

Figure 6. Frequency distribution of antibody levels, as shown by absorbance (630nm), of 64 penguins from the 2004-2005 field seasons as compared to 181 penguins from 2008 2009 field seasons. Positive cut-off indicated by dotted line at an absorbance of 0.044. 


\section{TABLES}

\begin{tabular}{|c|c|c|c|c|}
\hline 2008-2009 & & & & \\
\hline Site & Total no. & Positive no. & $\begin{array}{c}\text { Positive } \\
(\%)\end{array}$ & $\begin{array}{c}\text { Absorbance } \\
\text { range }\end{array}$ \\
\hline EI Muneco & 16 & 15 & 93.8 & $0.025-0.749$ \\
\hline Punta Espinosa & 28 & 28 & 100 & $0.049-0.295$ \\
\hline Cabo Douglas & 5 & 5 & 100 & $0.055-0.977$ \\
\hline Canones Sur & 15 & 15 & 100 & $0.047-0.212$ \\
\hline Fondeadero Mangle & 37 & 37 & 100 & $0.060-0.578$ \\
\hline Islas Marielas & 34 & 31 & 91.2 & $0.035-2.503$ \\
\hline Caleta Iguana & 30 & 29 & 96.7 & $0.043-0.249$ \\
\hline Puerto Villamil & 16 & 16 & 100 & $0.049-1.807$ \\
\hline Total & 181 & 176 & 97.2 & $.025-2.503$ \\
\hline
\end{tabular}

Table 1. Seroprevalence of anti-Plasmodium immunoglobulins in wild, Galapagos penguins. Positive for anti - Plasmodium spp. antibodies is determined as an absorbance value equal to or above $0.044(630 \mathrm{~nm})$ by ELISA. This value is equal to the mean absorbance +3 SD of the standard at 1:1600 dilution.

\begin{tabular}{ccccccc}
\hline Year & & n & Mean & Median & SD & IQR \\
\hline \hline 2008-09 & Total & 181 & 0.167 & 0.108 & 0.252 & 0.074 \\
\hline & Adult & 149 & 0.171 & 0.111 & 0.264 & 0.067 \\
\hline & Juvenile & 24 & 0.162 & 0.088 & 0.217 & 0.105 \\
\hline & Unknown age & 8 & 0.105 & 0.098 & 0.046 & 0.076 \\
\hline & Adult & 64 & 0.184 & 0.166 & 0.101 & 0.09 \\
\hline
\end{tabular}

Table 2. Descriptive statistics for antibody distributions, as shown by absorbance, of all individuals tested, separated by year and age class. 


\begin{tabular}{|c|c|c|c|c|c|}
\hline $\begin{array}{c}\text { Recapture } \\
\text { comparisons }\end{array}$ & \multicolumn{5}{|c|}{ Absorbance values } \\
\hline Site & $\begin{array}{c}\text { Penguin } \\
\text { ID }\end{array}$ & 2004-2005 & 2008 & 2009 & $\begin{array}{c}\text { Difference } \\
(\%)\end{array}$ \\
\hline Cabo Douglas & 2506 & 0.167 & & 0.103 & -6.4 \\
\hline Caleta Iguana & 1671 & 0.146 & 0.043 & & -10.3 \\
\hline Fondeadero Mangle & 2505 & 0.165 & 0.093 & & -7.2 \\
\hline Fondeadero Mangle & 5471 & & 0.143 & 0.125 & -1.8 \\
\hline Fondeadero Mangle & 5480 & & 0.092 & 0.235 & 14.3 \\
\hline Fondeadero Mangle & 1081 & & 0.101 & 0.082 & -1.9 \\
\hline Islas Marielas & 1630 & 0.325 & 0.113 & & -21.2 \\
\hline Islas Marielas & 2519 & 0.077 & 0.239 & & 16.2 \\
\hline Puerto Villamil & 5516 & & 0.096 & 0.100 & 0.4 \\
\hline Punta Espinosa & 5488 & & 0.134 & 0.102 & -3.2 \\
\hline
\end{tabular}

Table 3. Absorbance value comparisons of individuals sampled in more than one year.

Positive for anti-Plasmodium antibodies is determined as an absorbance value equal to or above $0.044(630 \mathrm{~nm})$ by ELISA. This value is equal to the mean absorbance $+3 \mathrm{SD}$ of the standard at 1:1600 dilution. *Highlighted values indicate individuals that tested as positive by PCR. 


\begin{tabular}{|c|c|c|c|c|c|c|}
\hline \multirow{2}{*}{$\begin{array}{c}\text { 2008-2009 } \\
\text { Site }\end{array}$} & \multicolumn{5}{|c|}{ No. of $P C R$ positive penguins } & \multirow[b]{2}{*}{$(\%)$} \\
\hline & $\begin{array}{c}\text { Total no. } \\
\text { of } \\
\text { penguins }\end{array}$ & $\begin{array}{c}\text { Waldenström } \\
\text { only }\end{array}$ & $\begin{array}{c}\text { Perkins \& } \\
\text { Schall } \\
\text { only }\end{array}$ & Both & $\begin{array}{c}\text { Total } \\
\text { no. } \\
\text { positive }\end{array}$ & \\
\hline El Muneco & 16 & 1 & 0 & $\mathbf{0}$ & 1 & 6.3 \\
\hline $\begin{array}{c}\text { Punta } \\
\text { Espinosa } \\
\end{array}$ & 28 & 1 & $\mathbf{0}$ & 1 & 2 & 7.1 \\
\hline $\begin{array}{c}\text { Cabo } \\
\text { Douglas } \\
\end{array}$ & 5 & $\mathbf{0}$ & $\mathbf{0}$ & $\mathbf{0}$ & $\mathbf{0}$ & $\mathbf{0 . 0}$ \\
\hline Canones Sur & 15 & $\mathbf{0}$ & $\mathbf{0}$ & 1 & 1 & 6.7 \\
\hline $\begin{array}{c}\text { Fondeadero } \\
\text { Mangle }\end{array}$ & 37 & 2 & 1 & 1 & 4 & 10.8 \\
\hline $\begin{array}{c}\text { Islas } \\
\text { Marielas } \\
\end{array}$ & 34 & $\mathbf{0}$ & 1 & 1 & 2 & 5.9 \\
\hline $\begin{array}{c}\text { Caleta } \\
\text { Iguana } \\
\end{array}$ & 30 & 1 & $\mathbf{0}$ & $\mathbf{0}$ & 1 & 3.3 \\
\hline $\begin{array}{c}\text { Puerto } \\
\text { Villamil } \\
\end{array}$ & 16 & 1 & 1 & 4 & 6 & 37.5 \\
\hline Total & 181 & 6 & 3 & 8 & 17 & 9.4 \\
\hline
\end{tabular}

Table 4. Total number of penguins that tested positive for the presence of Plasmodium parasites by PCR. Total number of individuals that tested positive with the following PCR primers: Waldenström primers only, Perkins \& Schall primers only and individuals that tested positive on both methods. 